\title{
Obscure: criação de marca com foco no estilo skate de vestir
}

\section{Obscure: brand creation with a focus on skateboarding style of dressing}

\author{
Alisson de Oliveira Porto ${ }^{[1]}$, \\ Nadia Miranda Leschko (orientadora) ${ }^{[2]}$
}

\begin{abstract}
Resumo: Este artigo apresenta os resultados da etapa prática de um trabalho de conclusão de curso. O trabalho teve como objetivo estudar e entender conceitos de marca, identidade visual e posicionamento de marca, a fim de aplicá-los na criação da marca de vestuário estilo skate denominada "Obscure". Para tanto, foi feita revisão bibliográfica de autores que abordam o assunto.

Palavras-chave: Marca. Identidade visual. Posicionamento de marca. Vestuário skate.

Abstract: This article presents the results of the practical stage of a course completion work. The work aimed to study and understand brand concepts, visual identity and brand positioning in order to apply them in the creation of the skate style clothing brand called "Obscure". To this end, a bibliographic review of authors who address the subject was performed.
\end{abstract}

Keywords: Mark. Visual identity. Brand positioning. Clothing skateboarding.

[1] Graduado em Design Gráfico, UFPEL.alisson_olvporto@hotmail.com

[2] Doutora em Design, PUC-RIO.nadiales@gmail.com 


\section{INTRODUÇÃO}

O trabalho de conclusão de curso que apresentamos nesse artigo abordou o estilo skate de se vestir, marca, identidade visual e posicionamento de marca, aplicando esses conceitos na concepção de uma marca de vestuário estilo skate.

Foi intitulado OBSCURE: CRIAÇÃO DE MARCA COM FOCO NO ESTILO SKATE DE VESTIR e apresentado no dia nove de julho de 2019, sob orientação Nadia Miranda Leschko.

Nos dias de hoje o esporte é mais aceito pela sociedade, tendo suas demandas atendidas pelo poder público através de construção de skateparks e criação de uma política pública própria.

A pesquisa foi norteada pela seguinte questão: como criar uma marca de vestuário estilo skate para vendas online com foco na redução de preços pra venda?

Definimos para esse trabalho o uso da expressão "vestuário estilo skate" para se referir à forma de se vestir inspirada no esporte. A expressão "vestuário skate", sem a palavra estilo, poderia dar a entender que a marca se ocuparia de criação e venda de roupas apenas para a prática do esporte, reduzindo o foco de atuação. Assim, foi ampliado o universo da marca para quem se identifica com o estilo skate de se vestir, mas não necessariamente pratica o esporte.

$O$ trabalho foi organizado conforme a seguinte estrutura:

- "Conceituações": marca, identidade visual e posicionamento de marca", foi feita uma breve apresentação dos conceitos básicos de marca, identidade visual e posicionamento de marca para situar o leitor quanto ao funcionamento de uma marca, como ela é criada, normatização da marca e o posicionamento que a marca irá adotar.

- "Concepção do briefing da marca": iniciamos a aplicação da etapa da metodologia de Wheeler (2012), etapa de condução de pesquisa e esclarecimento da estratégia. Também definimos o briefing que norteou e ajudou a fazer o posicionamento da marca Obscure. 
- "Criação da marca: naming, marca e pontos de contato": será mostrado o processo de naming (concepção do nome) da marca Obscure, sendo a sequência da metodologia de Wheeler (2012) a partir da etapa 3 que é o design de identidade e etapa 4 que são os pontos de contato.

- "Conclusão": onde serão retomados os objetivos do trabalho, relembrando todo o percurso, fazendo análises críticas dos resultados e dizendo qual foi o aprendizado adquirido com este trabalho, ressaltando também as expectativas futuras do projeto.

\section{MARCA}

Marca, basicamente, consiste de um desenho ou imagem que associada a uma tipografia que assimilamos e agregamos valor ao longo do tempo, como a Coca Cola e McDonald's.

Segundo a autora Consolo, o significado de marca é:

Uma mensagem que exprime uma identidade, uma tomada de posição, a qual oferece uma promessa aos seus públicos de interesse, que é entregue por meio de produtos ou serviços. E seu reconhecimento cresce quando a "entrega" corresponde à promessa feita. (CONSOLO, 2015, p. 32).

Marca também pode ser definida como um produto, empresa ou serviço que são representados por um símbolo e/ou logotipo, que com o tempo, devido à interação, experiências e contato do público com a marca, acabamos nos tornando consumidores e nos familiarizando com ela. Daí em diante pode passar a ter um grande valor para cada consumidor ou para grupos de consumidores.

Um dos pontos chave da marca é a diferenciação perante os seus concorrentes. Um exemplo de marcas que fazem isso, gerando uma grande disputa para ver quem se torna líder de mercado mundial, são as marcas Adidas e Nike, ambas de roupas esportivas. Elas usam os maiores jogadores de futebol da atualidade para divulgar suas marcas. Ambos ostentam o título de primeiro e segundo melhor jogador de futebol do 
mundo. Isso gera uma rivalidade maior, influenciando os fãs a escolher entre um ou outro.

Segundo Wheeler (2012 p.12) as marcas possuem três funções principais. São elas:

Navegação: As marcas ajudam os consumidores a escolher dentre uma enorme quantidade de opções; Segurança: As marcas comunicam a qualidade intrínseca do produto ou serviço e dão segurança ao cliente de que ele está tomando a decisão certa. Envolvimento: As marcas usam imagens, linguagens e associações para estimular os clientes a se identificar com a marca.

Com a enxurrada de opções que são oferecidas aos consumidores, junto a promessas e ofertas, é difícil estabelecer um diferencial que defina que é aquele produto e não o outro que será escolhido para consumo. Afinal, pode-se dizer que alguns produtos hoje em dia são muito semelhantes e diferem um dos outros em um aspecto essencial: a marca.

\section{IDENTIDADE VISUAL}

É o agrupamento dos elementos que irão padronizar visualmente o nome do produto ou serviço, mostrando e exaltando o posicionamento da marca. É a forma que se consegue configurar esses elementos em uma linguagem única. Peón (2001, p. 15) define como:

Sistema que normatiza e proporciona unidade e identidade a todos os itens de apresentação de um dado objeto, através de seu aspecto visual. Este objeto pode ser uma empresa, um grupo ou uma instituição, bem como uma ideia, um produto ou um serviço.

A identidade transmite a finalidade e a definição da marca, mostrando as ações, objetivos, sentidos e conceitos. Segue abaixo os princípios de identidade estabelecidos por Vásquez (2006, p. 56): 
- Única e intransferível. Toda identidade é pertencente de uma marca específica. Não existem duas marcas com a identidade idêntica, pode ser copiado um produto, mas é muito difícil copiar a sua essência.

- Atemporal e constante. Aidentidade não tem período nem limite de validez, porém ela deve ser estável no tempo.

- Consistente e coerente. Uma identidade deve ter firmeza em seus princípios, valores e em todos seus elementos constitutivos. Ao mesmo período em que deve existir mecanismos entre as partes, sendo coincidente e compatíveis entre eles.

- Objetivo e adaptável. A definição de uma boa identidade deve ser direta em seus propósitos, porém a sua comunicação deve ser adaptada de acordo com o seu público-alvo e sua cultura local, uma vez que a globalização das marcas traz como consequência a introdução delas em países muito diferentes do original. "O idioma pode mudar, as mensagens podem ser adaptadas ao modo de viver da sociedade local, mas a identidade deve permanecer a mesma".

Segundo Peón (2001) para a formação de uma identidade visual deve-se levar dois elementos como base: os primários, que são aqueles nos quais se baseiam todos os demais e cuja veiculação alternada nas aplicações é fundamental para a atividade do sistema. São eles: logotipo, que é o desenho que representa uma marca; o símbolo que substitui ou sugere algo e a marca que é a representação simbólica de uma entidade. Já os secundários são: alfabeto e cores institucionais. Também acrescenta que a palavra identificação é igual ao reconhecimento de identidade. Quando a identidade visual é farta, toda nossa atenção se dirige ao objeto, facilitando e ajudando na pregnância que é algo que produz forte impressão. A autora acrescenta ainda que quando se observa uma empresa e afirma que ela não possui identidade visual, significa que ela possui aspectos que a fragilizam e que não tem elementos suficientes para que o cliente/consumidor consiga remeter ou associar ela a algo. 


\section{POSICIONAMENTO DA MARCA}

Uma marca bem posicionada é aquela que tem as suas grandes vantagens e características reveladas e afirmadas na mente do público.

Segundo Wheeler (2012, p. 24):

Posicionamento é uma estratégia desenvolvida parar criar aberturas em um mercado que está sempre mudando, um mercado no qual os consumidores estão saturados dos produtos e mensagens. O posicionamento tira vantagens das mudanças nas tendências, tecnologia entre outros, para encontrar novos meios de chamar atenção ao público.

Wheeler (2012, p.24) acrescenta que o posicionamento está conectado com o que se faz com a mente do cliente potencial e não com o que se faz com um produto em si. É essencial posicionar o produto na mente do cliente, porém precisa ser algo distinto e novo. É indispensável manipular o que já está na imaginação das pessoas e reatar as conexões existentes.

A imagem criada pela empresa/marca pode, às vezes, não estar em harmonia com a imagem formada na cabeça dos clientes consumidores, por isso a avaliação da imagem e o posicionamento da marca têm que ser revisados com muita frequência pelos gestores das marcas.

Os consumidores consideram como algo real todas aquelas impressões que se formam nas suas cabeças e acreditam nelas fielmente. A maneira com que os clientes percebem as ofertas existentes no mercado e as avaliam junto de outras, acaba gerando o posicionamento competitivo.

\section{METODOLOGIA APLICADA AO ESTUDO DE CASO}

A metodologia de criação de marca usada na pesquisa foi criada pela designer Alina Wheeler em seu livro "Design de Identidade de marca (2012)". Foi feito um resumo de cada etapa, trazendo apenas o que era essencial para a criação da marca. A autora define esse processo em 5 etapas: condução 
da pesquisa, esclarecimento da estratégia, design de identidade, criação de pontos de contato e gestão de ativos.

Após sintetizar a coleta dos dados e relacioná-las com a identidade visual, refinamos os aspectos significativos para a marca a ser criada. Notou-se que essas marcas existentes não davam muita atenção para pessoas que gostam do vestuário estilo skate, inseridas nas classes sociais com menor poder aquisitivo. A partir dessa constatação, surgiu a ideia de fazer a criação de uma marca de vestuário estilo skate para quem gosta, mas não necessariamente pratica o esporte, que seja simples e direta, focando na redução de preços de compra para o consumidor e assim atingindo o público que as outras marcas não atingem.

Para melhor investigar as marcas do segmento de vestuário estilo skate, foi realizado um estudo de caso que Wheeler (2012) chama de auditoria da concorrência. É um processo dinâmico de coleta de dados, que examina as marcas através de suas mensagens principais e identidades da concorrência no mercado, de símbolos e taglines (pequena frase que fala do negócio em si) a anúncios e sites.

Esse levantamento de Wheeler (2012) é uma forma de compreender melhor as marcas concorrentes. As etapas do processo são: identificar os concorrentes; coletar informações/pesquisa; determinar o posicionamento; identificar as mensagens principais; examinar a identidade visual; documentar a identidade; examinar a estratégia do nome; examinar a hierarquia de marcas; vivenciar a concorrência e sintetizar o que foi aprendido.

Está análise foi muito útil, porque além de conhecer e investigar a fundo as marcas, aprendeu-se muito com a diferença da estética, posicionamento e atitude, sendo possível sintetizar para orientar a criação da marca Obscure.

\section{CONCEPÇÃO DO BRIEFING DA MARCA}

Para averiguar os aspectos de cada marca e esclarecer os elementos relevantes para o projeto, foi elaborado o briefing, 
que funciona como um mapa para quem está projetando, que deve ser direto e estratégico.

Foi utilizado o esquema de briefing da autora Wheeler (2012), composto pelos seguintes itens: grande ideia ou essência da marca; atributos que são as características da marca; visão e missão; principais produtos ou serviços; principais concorrentes; vantagem competitiva; stakeholders principais; proposta de valor e mercado alvo. O briefing elaborado para a marca Obscure é mostrado a seguir.

\section{BRIEFING DA MARCA OBSCURE}

VISÃO E MISSÃO: A missão é fornecer produtos do estilo skate a preços acessíveis e a visão é a promoção do estilo de vida skate na forma de se vestir.

GRANDE IDEIA: Obscure é uma marca de vestuário estilo skate com foco no baixo custo em relação às suas concorrentes e destinada a quem curte, mas não necessariamente pratica o esporte.

ATRIBUTOS: Misteriosa, Básica, reservada, discreta, confortável, urbana e contemporânea.

PROPOSTA DE VALOR: Quem busca pela marca Obscure, busca o estilo skate, básico, discreto, simples, urbano, contemporâneo e confortável de se vestir sem pagar caro por isso. Obscure é a marca para pessoas reservadas, que não se mostram de imediato e que são um tanto misteriosas.

MERCADO ALVO: Público jovem, de ambos os sexos na faixa etária de 15 a 24 anos, que recebem entre 1 a 3 salários mínimos. O intuito é que a marca abranja todo Brasil, pois será divulgada pelos meios da internet (Site, Facebook e Instagram). 
PRINCIPAIS CONCORRENTES: HIGH, Mess, Qix. Todas são concorrentes diretas, a High do vestuário estilo skate, a Mess do vestuário estilo skate e local, e a Qix do vestuário estilo skate e baixo preço.

VANTAGEM COMPETITIVA: Custo baixo em relação a todas as outras marcas que tem em vista o mesmo foco: o estilo skate de se vestir.

PRINCIPAIS PRODUTOS OU SERVIÇOS: Venda de bonés, camisetas e moletons com foco na redução de custos, impressões só em uma cor e tecidos acessíveis, porém confortáveis e duráveis.

STAKEHOLDERS PRINCIPAIS: Proprietário (Designer e ilustrador da marca), funcionários, fornecedores (malharia, gráfica), clientes, parceiros e concorrentes.

\section{PROCESSO DE NAMING}

Comumente é o nome que inicia a conversa com o usuário e estará continuamente na mente dele em todas as experiências que ele terá com a marca. Sobre nomes de marca, Wheeler (2012) diz que:

\section{CC É um processo complexo, criativo, iterativo que requer certa experiência linguística, marketing, pesquisa e lei de marcas e patentes. (WHEELER, (2012, p.132)}

Para a construção do naming, foi utilizada a plataforma de compartilhamento de vídeos Youtube e encontrado o método 20/20/20, onde o especialista em e-commerce de Moda, Matheus Almeida ensina o passo a passo. São três passos: listar 20 palavras que tenham a ver com o tema da sua marca, fazer 20 perguntas a essas palavras e o terceiro e último passo é responder estas perguntas. Ao aplicar esse méto- 
do, surgiram algumas respostas complexas e palavras-chave para a criação da marca.

A palavra escolhida foi Obscure que significa obscuro. Foram listados os seus significados em um dicionário Houaiss, e ali a maioria das definições dadas, eram de qualidades negativas como, por exemplo; "medonho, tenebroso, pouco promissor, lúgubre, inquietador". Contudo, uma definição se sobressaiu e não foi considerado algo negativo para a criação de uma marca de vestuário. A definição dizia que obscuro significava algo "singelo, simples, humilde, de condição social modesta, sem nobreza". Daí em diante, essa definição foi aplicada no projeto e acabou se tornando os atributos que ajudaram a definir a criação da marca.

\section{DESIGN DA IDENTIDADE DA MARCA OBSCURE}

Sobre a responsabilidade de criar um design de identidade, Wheeler (2012) diz que:

Reduzir uma ideia complexa à sua essência visual requer perícia, foco, paciência e uma disciplina infindável. O designer pode examinar centenas de ideias antes de se concentrar em uma escolha final. Mesmo depois que essa ideia final emerge, o teste de sua validade dá início a mais uma rodada de exploração. (WHEELER, 2012, p. 134).

Wheeler (2012) define que a etapa do design de identidade é formada por: assinatura visual, cor, tipografia, som, movimento, aplicações de teste e apresentação.

A autora afirma que a tipografia é essencial para um programa de identidade eficaz. Uma imagem integrada e coerente de uma empresa é impossível sem uma tipografia que tenha uma personalidade especial e legibilidade inerente, redesenhada.

Para a marca Obscure, foi utilizada uma tipografia básica sem serifa e de espessura bold com o intuito de atribuir simplicidade. A fonte foi modificada na parte inferior. Foi feito um corte para passar uma ideia de discrição que a marca deseja. 
A autora também acrescenta que o logotipo é uma palavra em uma determinada fonte tipográfica, que pode ser normal, modificada ou aparecer inteiramente (fig. 1). Sobre a identidade visual, tentamos criar uma marca com certa discrição e direta. A ideia principal é que a marca seja formada e se sustente apenas pelo logotipo.

Obscure é a marca para pessoas reservadas, que não se mostram de imediato, que são um tanto misteriosas. É uma marca que expressa sua identidade através da simplicidade, optando pelo básico. São proposições de valores que o corte na tipografia quer reforçar. Proporcionando um estilo de vida skate de modo acessível.

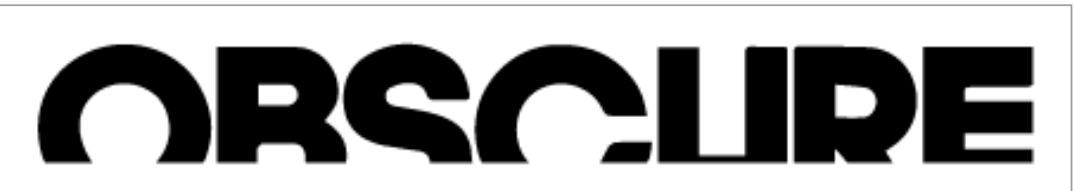

Figura 1: Logotipo da marca Obscure. Elaborado pelo autor.

Sobre a cor, Wheeler (2012) afirma que esta é utilizada para evocar emoções e expressar personalidades. Ela acaba estimulando a associação de marca e acelerando a sua diferenciação. Na marca Obscure os matizes escolhidos foram o preto, branco e cinza, todos tons neutros (fig. 2).

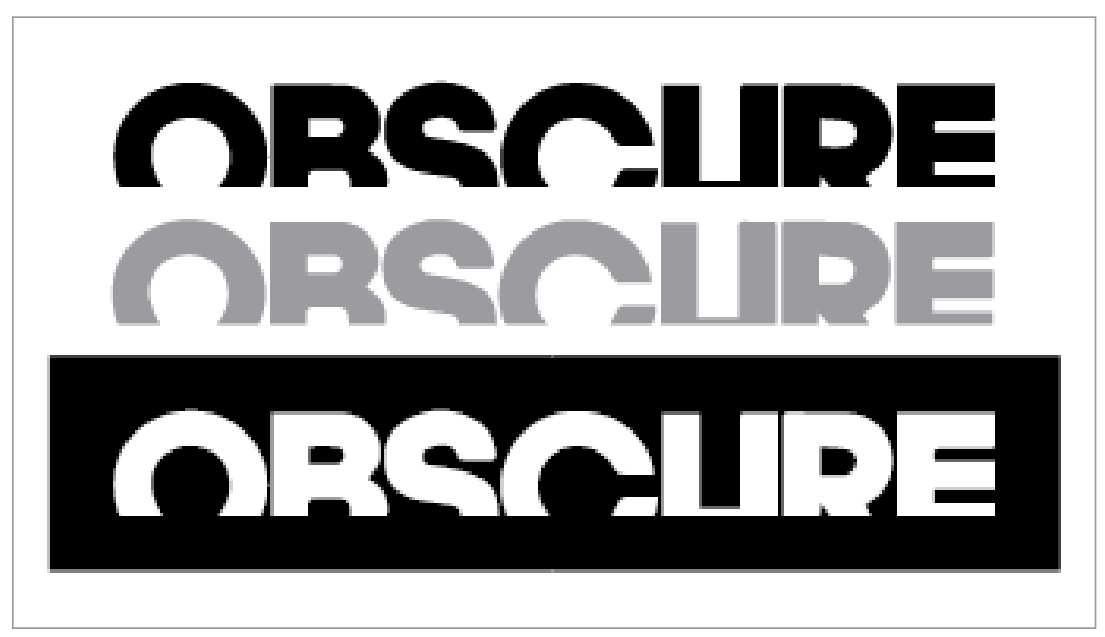

Figura 2: Cores da marca Obscure. Elaborado pelo autor. 
Por fim, Wheeler (2012) afirma que nenhuma marca pode ser apresentada em uma folha de papel em branco. Os tomadores de decisão precisam ver a identidade do mesmo modo que o cliente a veria. Seguindo essa premissa, a marca foi aplicada em um dos itens que a marca irá comercializar, uma camiseta (fig. 3).

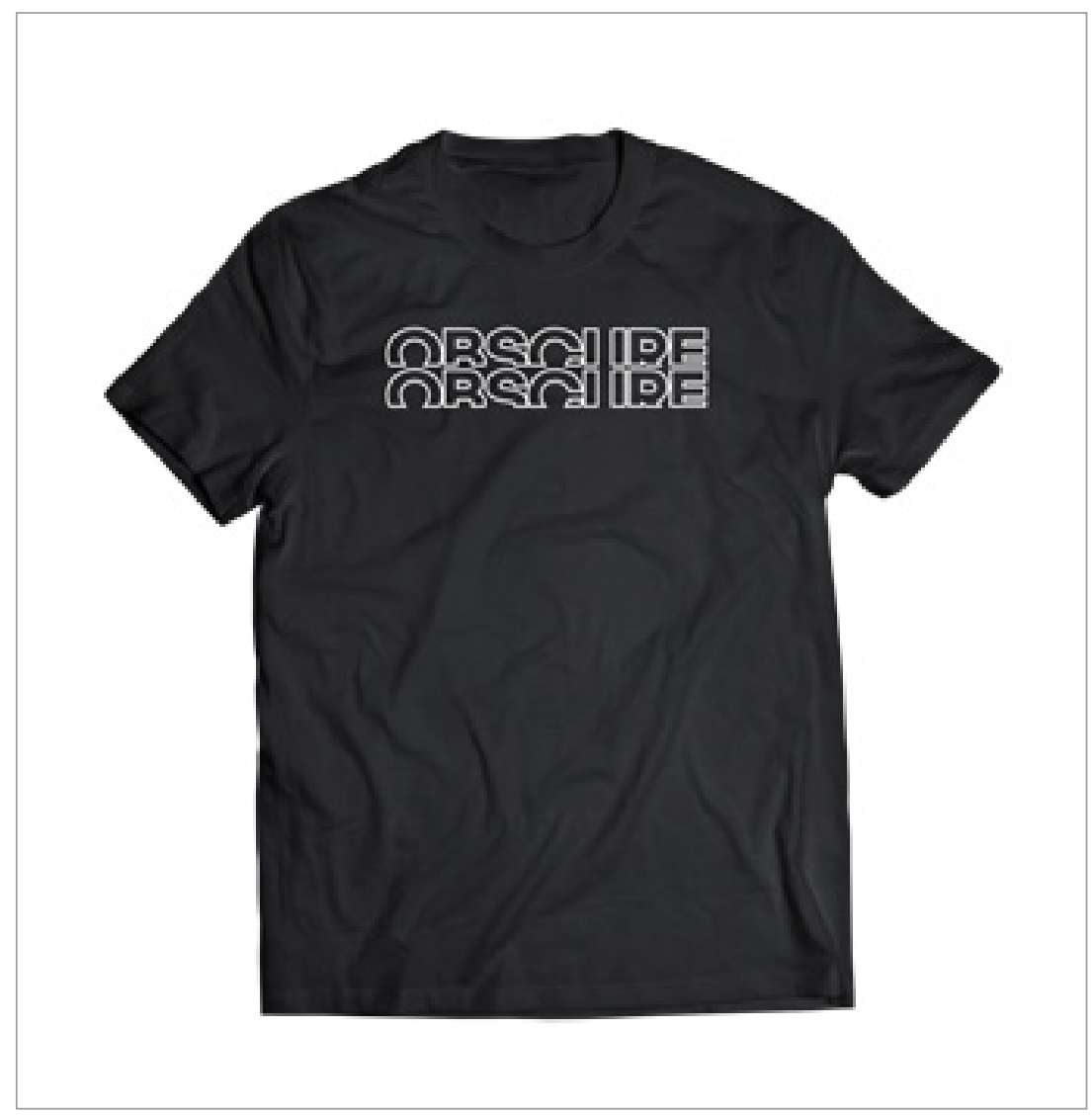

Figura 3: Aplicação da marca em camiseta. Elaborado pelo autor.

\section{PONTOS DE CONTATO}

Wheeler (2012) faz referência a aplicações da marca, destacando que o conceito norteador para a criação dos pontos de contato foi a redução do preço de venda em relação às marcas concorrentes. Foi feita uma pesquisa em gráficas na cidade de Pelotas/RS e via internet. Foram encontradas gráficas que fornecem impressão de malha por um preço justo. Já foi dito que a marca preza pelo simples, básico e acessível, 
por isso as peças comercializadas serão com impressões só em uma cor e tecidos acessíveis, porém confortáveis e duráveis. Apesar de serem peças simples, combinam com o estilo skate de vestuário. O boné será feito em dois tipos; aba curva e aba reta, os dois terão o logotipo cujo objetivo é promover a marca nas peças. As camisetas e o moletom são roupas folgadas e confortáveis, combinando com o estilo skate de vestir e também usam o logotipo para promover a marca (fig. 4 a 7).

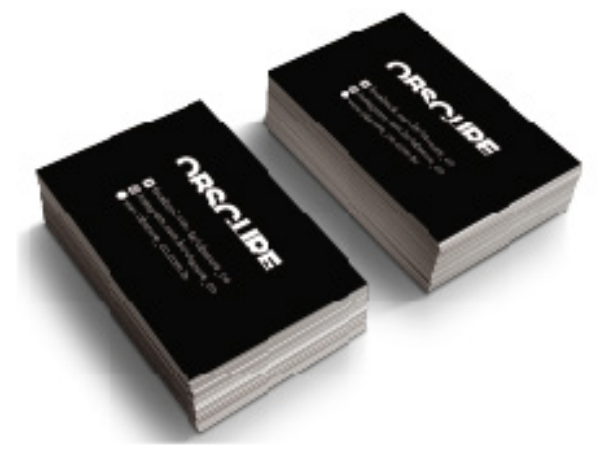

Material: Couche Fosco $350 \mathrm{~g}$ Formato: $90 \times 50 \mathrm{~mm}$ Impressäo: Offset, somente Frente

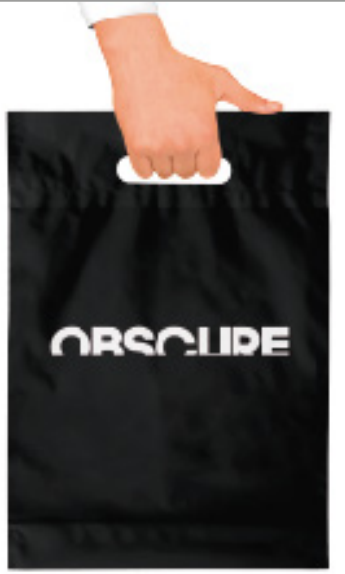

Material: Sacola plastica de Polietileno Formato: $39 \times 28 \times 9 \mathrm{~cm}$

Impressáo: Serigrafia, somente uma cor
Figura 4: Cartão de visita e embalagem. Elaborado pelo autor.

Figura 5: Bonés da marca Obscure. Elaborado pelo autor.
Aba Curva

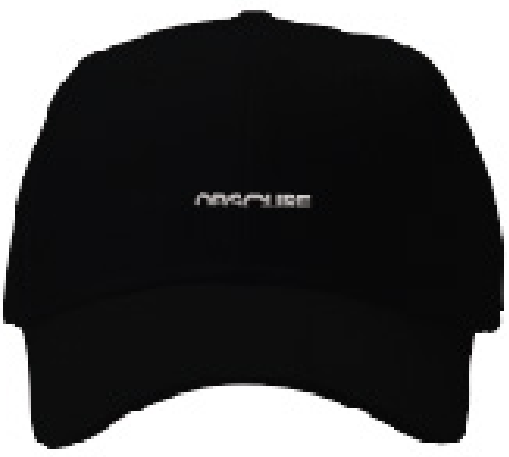

Aba Refa

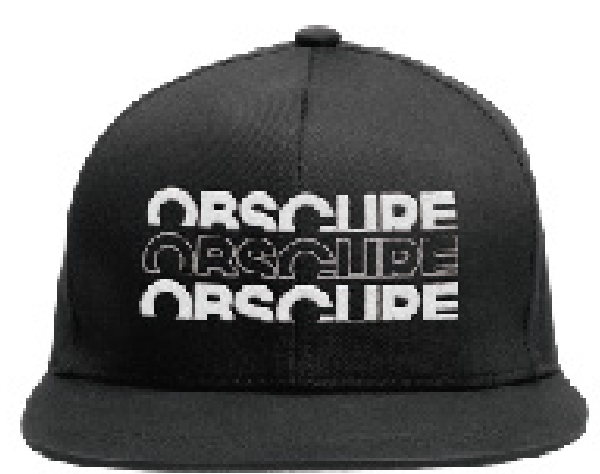

Material: Bones 100\% Algodāo

Impressão: Bordado Frontal

Valor de Venda: RS 65 


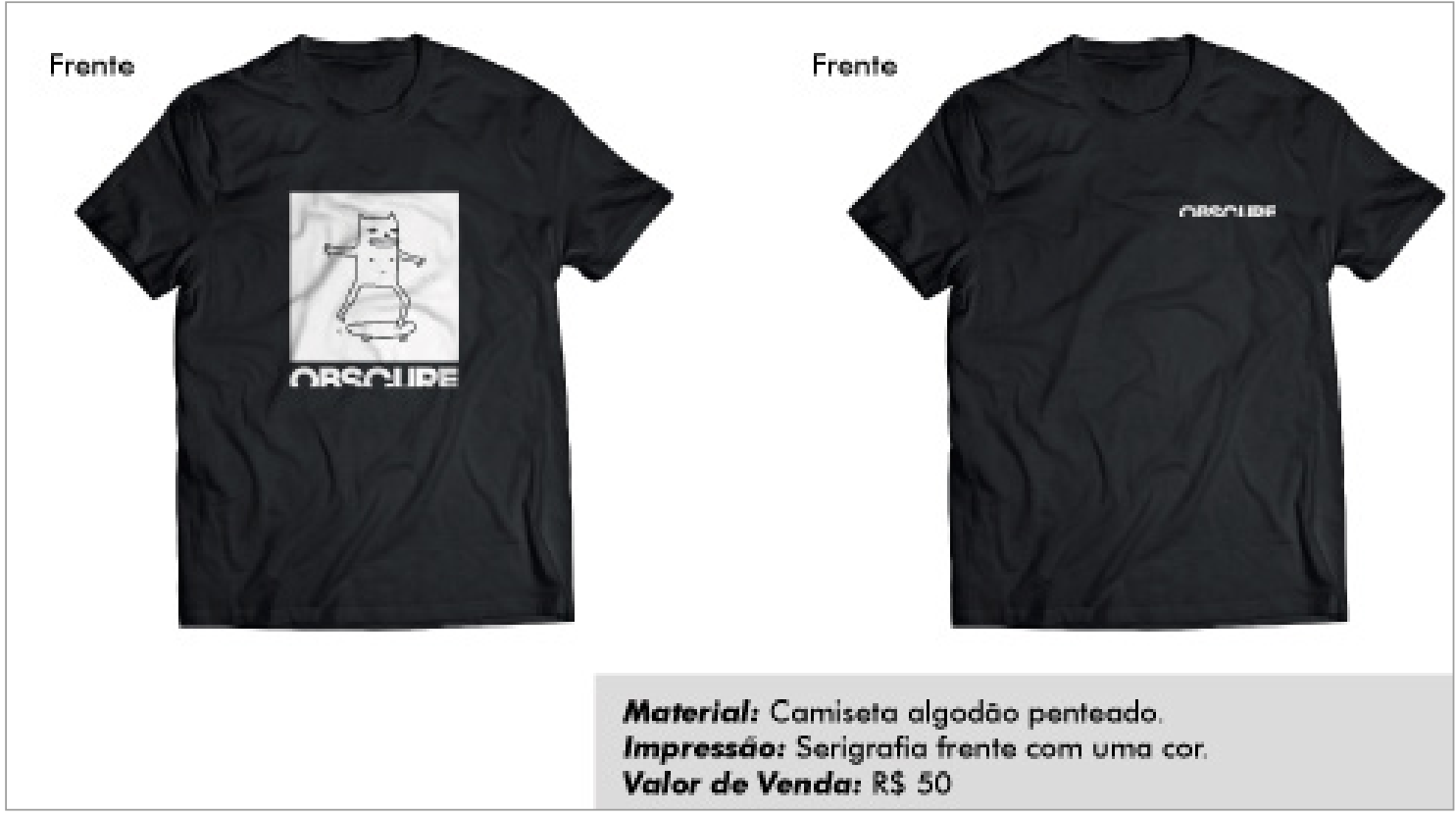

Figura 6: Camisetas da marca Obscure. Elaborado pelo autor.

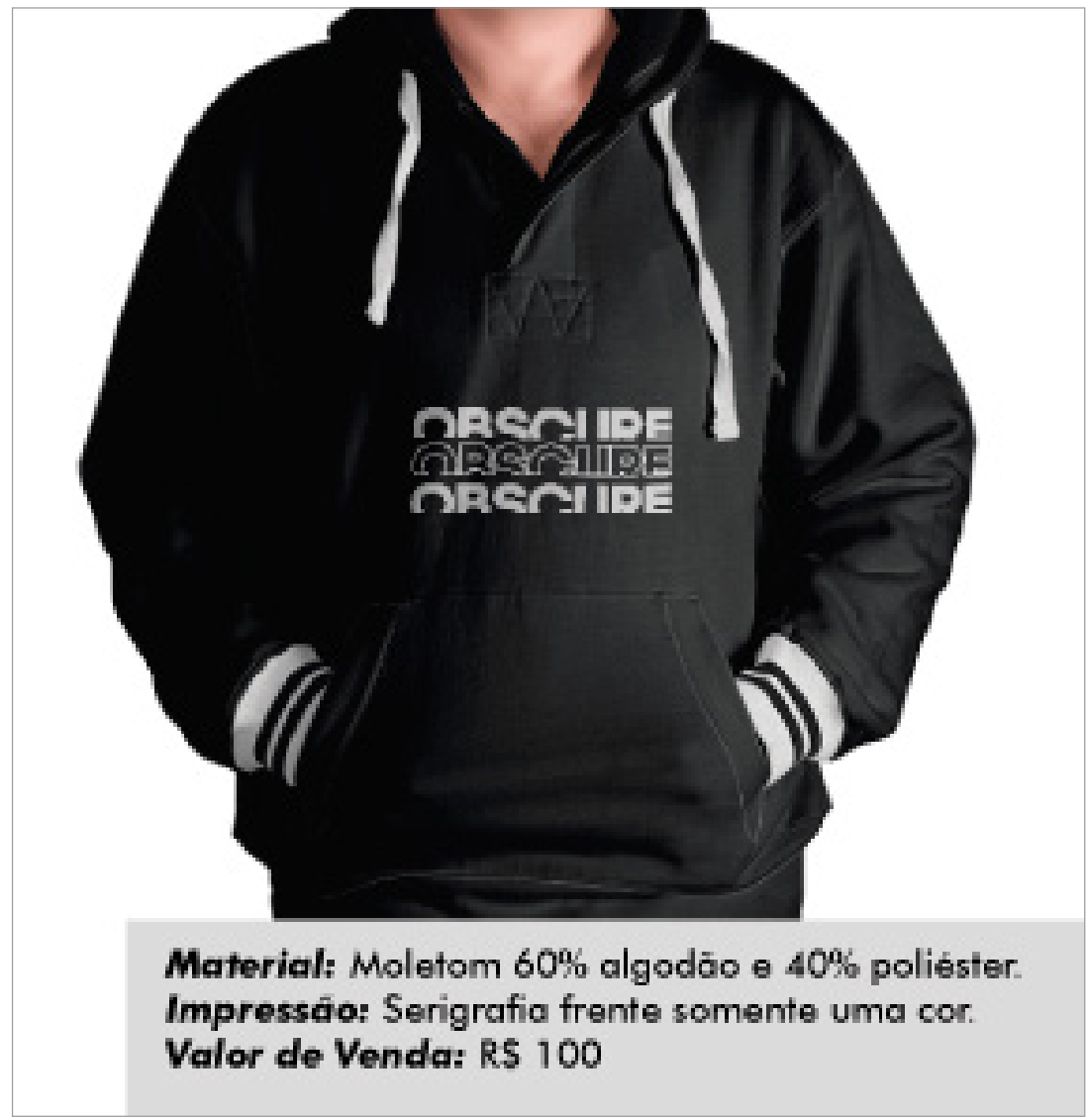

Figura 7: Moletom da marca Obscure. Elaborado pelo autor 


\section{CONCLUSÃo}

O produto final do projeto foi a criação de uma marca de vestuário estilo skate chamada Obscure, que foi normatizada e desenvolvida através de uma forma direta e simples.

O processo foi facilitado por o autor ter uma grande afinidade por identidade visual. Esta é uma das áreas mais abrangentes dentro do design, na qual dependendo do projeto é exigido diferentes habilidades, como: ilustração, tipografia, entre outras, que acaba proporcionando um certo nível de versatilidade. Sendo assim, esses foram os principais estímulos que proporcionaram o aprofundamento e o seguimento do projeto da marca.

A criação da marca está atrelada a uma motivação pessoal e profissional do autor deste artigo.

Os maiores aprendizados obtidos com a criação, foram o empenho com o conteúdo estudado, mostrando o interesse profissional a longo prazo. Tornar-se referência e objeto de estudo para as próximas criações dentro do curso, servindo assim de motivação para que outras pessoas realizem o sonho de criar sua própria marca e a por em prática no mercado.

O curso de Design Gráfico só tem a ganhar e crescer com trabalhos como este, pois servem de vitrine para pessoas de fora terem o conhecimento de projetos elaborados dentro da Universidade e vislumbrem as criações feitas em nosso curso e, consequentemente, desfrutem das práticas já aplicadas e expostas na rua.

Conclui-se com este artigo que é possível sim, criar uma marca de vestuário estilo skate, que seja simples e básica e que caiba no bolso do consumidor. 


\section{REFERÊNCIAS BIBLIOGRÁFICAS}

CONSOLO, Cecília. Design Estratégico,

do símbolo à Gestão da Identidade

Corporativa. São Paulo: Blucher, 2015.

PEÓN, Maria Luísa. Sistemas de identidade

visual. 3.ed. Rio de Janeiro: 2AB, 2003.

VÁSQUEZ, Ruth. Identidade de marca, gestão

e comunicação. São Paulo, 2006

WHEELER, Alina. Design de identidade da marca: um guia completo para criação, construção e manutenção

de marcas fortes. Porto Alegre: Bookman, 2012. 